\title{
Cardiac arrest seen by the relatives of the cardiology patients: high risk and poor preparation
}

Simone Savastano, MD; Aurora I Danza, MD; Enrico Baldi, MD; Laura Scelsi, MD; Annalisa Turco, MD; Claudia Raineri, MD; Stefano Ghio, MD; Franca Contin, RN; Gaetano M De Ferrari, MD; Luigi Oltrona Visconti,MD.

Purpose The majority of cardiac arrests occurs at home, so the relatives of the cardiology patients are more likely to witness an event. We sought to assess their perceived risk of facing a cardiac arrest and their feeling of adequacy to recognize a cardiac arrest and to perform CPR.

Methods. Before the in-office visit of our heart failure patents 208 relatives were asked to express in a scale from 0 to 100 both the perceived risk to witness a cardiac arrest and their feeling of adequacy to recognize the cardiac arrest and to start CPR alone or guided by the dispatcher.

Results. The majority of the enrolled relatives were female $(75 \%)$; mean age was $50 \pm 12.5$ years. About one half $(55 \%)$ of them live with the patient and only the $22 \%$ have already attended a CPR course. Median perceived risk to face a cardiac arrest was 50/100 (IC 95\% 44.7- 50), as well as the perceived risk to witness their relative's cardiac arrest $50 / 100$ (IC 95\% 40-50). The median of their adequacy to recognize a cardiac arrest was 20/100 (IC95\% 1020); to perform CP Rwas 0/100 (IC 95\% 0-10) and $30 / 100$ (IC95\% 20-50) if guided by phone. Those who attended a CPR or CPR/AED course showed an higher perception of adequacy both in recognition of cardiac arrest $[50 / 100$ (IC95\% 50-70) vs $10 / 100$ (IC95\% 2-20) $p<0.001]$ and in performing CPR alone $\left[\begin{array}{llllll}50 / 100 & (\mathrm{IC} 95 \% & 50-71) & \text { vs } 0 / 100 & \text { (IC95\% } & 0-0\end{array}\right)$ $\mathrm{p}<0.001]$ or assisted by the dispatcher $[80 / 100$ (IC95\% 60-90) vs 20/100 (IC95\% 10-30) $p<0.001]$.

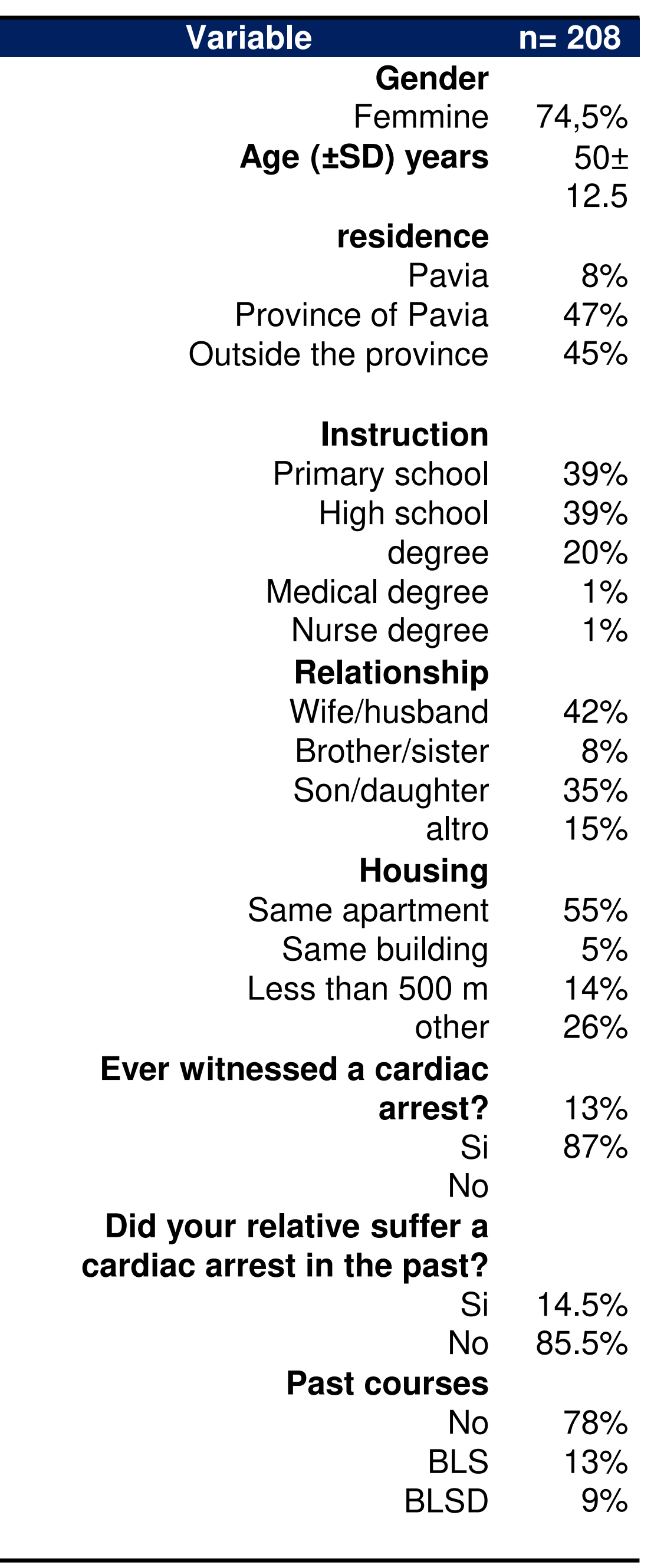

RESUSCITATION 2018

New technologies in resuscitation

20-21- 22 September $\bullet$ Bologna $\bullet$ Italy
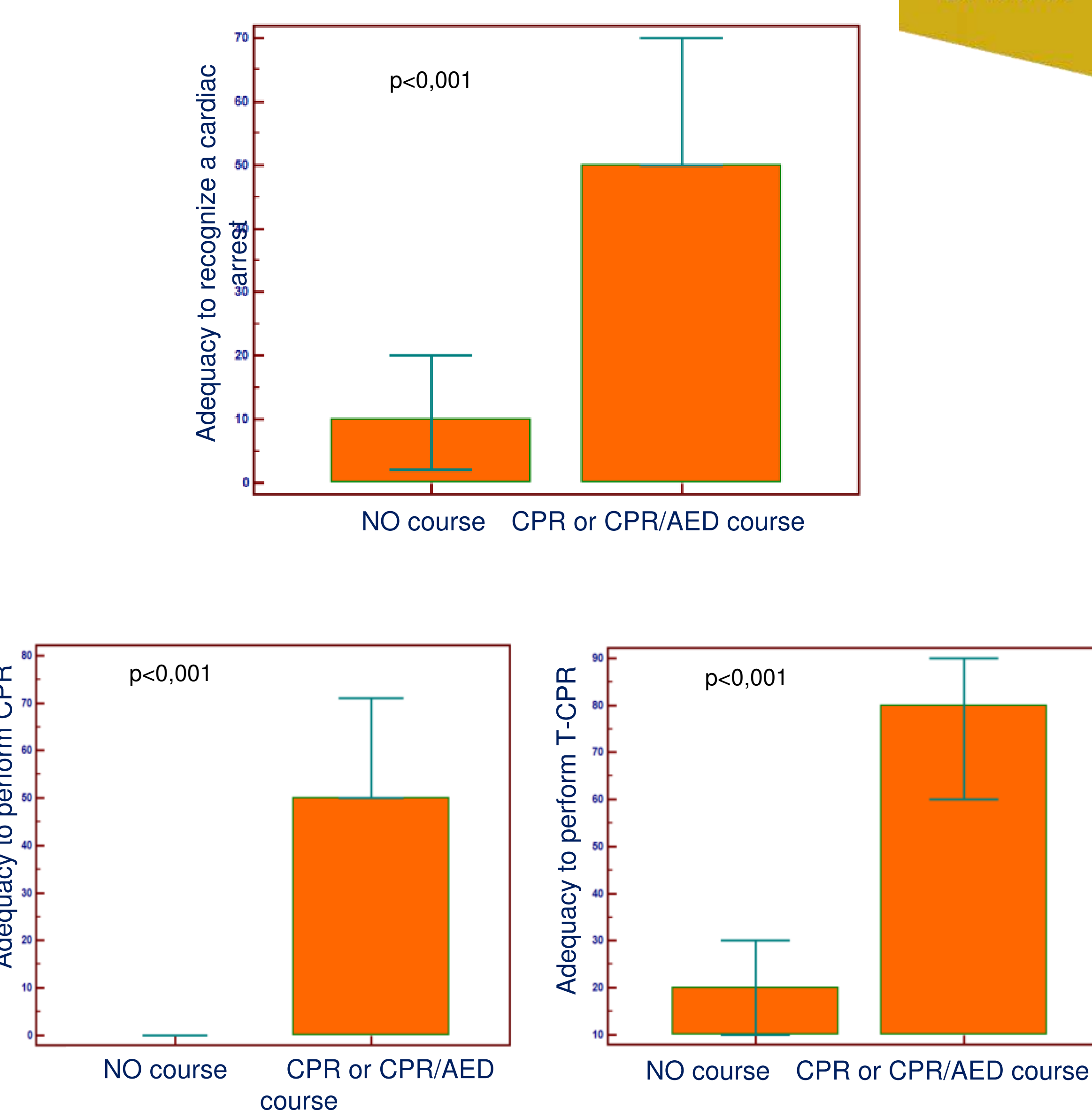

Conclusions. The relatives of our cardiology patients perceived a high risk in front of a very low adequacy to manage a cardiac arrest. The divisions of Cardiology should provide or suggest CPR courses to the relatives of their patients to enhance their competency about life-saving maneuvers. 